
France de l'Est, Luxembourg)

\title{
Jean-Noël Salomon, 2000, Précis de Karstologie
}

Presses Universitaires de Bordeaux, Collection « Scieteren », Pessac, 250 p.

\section{André Weisrock}

\section{OpenEdition}

\section{Journals}

Édition électronique

URL : http://journals.openedition.org/rge/3952

DOI : $10.4000 /$ rge.3952

ISSN : 2108-6478

Éditeur

Association des géographes de l'Est

Édition imprimée

Date de publication : 1 septembre 2001

ISSN : 0035-3213

\section{Référence électronique}

André Weisrock, « Jean-Noël Salomon, 2000, Précis de Karstologie », Revue Géographique de l'Est [En ligne], vol. 41 / 4 | 2001, mis en ligne le 23 juillet 2013, consulté le 23 septembre 2020. URL : http:// journals.openedition.org/rge/3952 ; DOI : https://doi.org/10.4000/rge.3952

Ce document a été généré automatiquement le 23 septembre 2020.

Tous droits réservés 


\section{Jean-Noël Salomon, 2000, Précis de Karstologie}

Presses Universitaires de Bordeaux, Collection « Scieteren », Pessac, 250

p.

André Weisrock

\section{RÉFÉRENCE}

Salomon J.-N. - Précis de Karstologie, Presses Universitaires de Bordeaux, Collection «Scieteren », Pessac, 2000, 250 p.

1 Il s'agit du premier ouvrage de synthèse en langue française sur la très vaste question de la géomorphologie karstique, depuis l'excellent Pays et paysages du calcaire de Jean Nicod (1972). C'est un regard essentiellement géographique et synthétique qui est offert au lecteur, en fonction d'un plan très solidement charpenté en 12 chapitres que l'on peut regrouper selon trois parties inégales en volume :

2 a) une description des phénomènes et paysages karstiques (chapitres 3, 4 et 5, qui traitent des formes superficielles : lapiés, dépressions fermées, vallées karstiques); b) la recherche des explications aux formes et paysages karstiques, de loin la partie essentielle (chapitres 1, 2, puis surtout 6, 7, 8, 9, 10).

Les chapitres 1 et 2 (facteurs lithologiques et dissolution des carbonates) constituent en fait une partie générale encore introductive. J.N. Salomon retient ensuite 5 ensembles de facteurs décisifs sur la formation, le fonctionnement et la différenciation des karsts dans le monde :

51 - « le rôle de la structure et de la tectonique ». Faut-il voir dans ce titre une influence du langage géologique? (les géomorphologues incluent en fait la tectonique - et la lithologie - dans les conditions structurales);

62 - «le rôle du relief, facteur des conditions hydrodynamiques", chapitre neuf qui insiste avec raison sur un paramètre assez négligé habituellement, mais qu'il est très 
difficile d'isoler du contexte tectonique d'une part, et du contexte hydrologique d'autre part ;

73 - «le fonctionnement hydrologique", chapitre tout à fait fondamental et qui démontre tout l'avantage que les karstologues ont tiré des apports de la spéléologie depuis 30 ans. Ce chapitre aurait cependant mérité une conclusion ;

4 - «l'influence climatique sur le karst » est abordée du double point de vue général (influences des facteurs climatiques) et régional (différenciation des karsts en fonction des domaines climatiques). Les pays tropicaux, arides et méditerranéens, que l'auteur connaît bien, se taillent la part du lion, mais pourquoi ne trouve-t-on pas de paragraphe sur les karsts du domaine tempéré océanique?

95 - «le karst et le facteur temps » constitue également une contribution originale discutant des vitesses de karstification et du problème des héritages. Peut-être auraiton pu la relier à l'étude des remplissages et des spéléothèmes, qui se trouve il est vrai dans le chapitre suivant ;

10 c) une dernière partie qui, globalement, pourrait s'intituler "l'homme et le karst", témoignant du souci de la géomorphologie karstique d'apporter sa contribution aux questions d'environnement et d'aménagement. Ce sont les chapitres 11 et 12, intitulés «les outils de la connaissance du karst » et «l'exploitation et la mise en valeur du karst ", où l'on trouve notamment un très intéressant tableau de la fréquentation des sites karstiques les plus visités dans le monde.

11 Les vieux spécialistes grincheux dont je fais hélas partie trouveront toujours quelque critique à ce genre d'entreprise: des oublis, une documentation scientifique (sans doute volontairement) incomplète, des réflexions et des synthèses systémiques que l'on serait en droit d'attendre plus poussées au sein d'un "Précis »; peut-être pourrait-on attendre aussi un nouveau glossaire des termes du vocabulaire karstique? Mais ce livre ne s'adresse pas à eux. Il est avant tout un manuel d'enseignement supérieur, soumis aux normes d'une collection scientifique, destiné aux étudiants ou à un public varié qui s'intéresse à la karstologie et à la spéléologie. Il se veut clair, accessible, intéressant, en un mot culturel. J.-N. Salomon, qui fréquente et étudie les karsts des cinq continents depuis plus de 20 ans, a amassé une documentation personnelle d'une grande richesse, qu'il nous fait généreusement partager : ne boudons pas notre plaisir !

\section{AUTEURS}

\section{ANDRÉ WEISROCK}

Université Nancy 2 